\title{
Nunca se puede decir lo más importante - Homenaje a Ricardo Piglia
}

\section{You Can Never Say the Most Important Thing - Tribute to Ricardo Piglia}

\section{MARIO RODRÍGUEZ FERNÁNDEZ}

\author{
Universidad de Concepción. Concepción, Chile. \\ Correo electrónico: mariorod@udec.cl
}

\begin{abstract}
El trabajo propone fundamentalmente que el relato de Piglia "Homenaje a Roberto Arlt" se desarrolla a través de una íntima conexión entre las llamadas "dos partes del relato": la pesquisa bibliográfica y "Luba" el supuesto inédito de Arlt. Hasta ahora la crítica no ha percibido claramente esta unión porque no ha trabajado con la idea del mismo Piglia sobre la existencia en toda narración breve de dos historias, la visible y la secreta. En los intersticios de la historia visible de la pesquisa bibliográfica se narra una de codicia y antiutópica, y en la de persecución contada en "Luba" otra secreta de redención y utópica. Para descubrir la oposición es necesario entenderlas como un conjunto. Hay por otra parte, elementos de unión: en las dos se narra una persecución, la persecución de un texto en una, la persecución de un hombre en la otra. Finalmente, hay un homenaje doble: la historia visible es un homenaje (ambiguo) a Arlt, la secreta, un homenaje (por la disposición de los dispositivos de narración) a Borges.
\end{abstract}

Palabras claves: Historia visible, historia secreta, persecución, homenaje, Arlt, Borges.

The work essentially proposes that Piglia's story "Tribute to Roberto Arlt" is developed through an intimate connection between the so-called "two parts of the story": the bibliographic research and "Luba" the unpublished assumption of Arlt. He has not perceived this union because he has not worked with Piglia's own idea about the existence in every brief narrative of two stories, the visible and the secret. In the interstices of the visible history of the bibliographic research is narrated one of greed and antiutopian, and in the persecution told in "Luba" another secret of redemption and utopian. To discover the opposition is necessary to understand them as a set. There are, on the other hand, elements of union: in both is narrated a persecution, the pursuit of a text in one, the persecution of a man in the other. Finally, there is a double homage: the visible history is a homage (ambiguous) to Arlt, the secret, a tribute (for the disposition of narrative devices) to Borges.

Key words: visible history, secret history, persecution, tribute, Arlt, Borges. 
"Esto que escribo es un informe, mejor dicho, un resumen: está en juego la propiedad de un texto de Roberto Arlt: de modo que voy a tratar de ser ordenado y objetivo. Yo soy el que descubrió el único relato de Arlt que ha permanecido inédito después de su muerte. El texto se llama 'Luba'. Arlt lo escribió aproximadamente entre el 25 de marzo y el 6 de abril de 1942", así comienza "Homenaje a Roberto Arlt" de Ricardo Piglia (Piglia 1994: 89).

El relato en el mismo principio sustrae el dato más importante para el lector y finaliza no entregándolo nunca, a excepción de algunas pistas que permitirían rescatarlo. Mi homenaje es una deriva de esta sustracción porque creo que los dispositivos empleados por Piglia para realizarla son maestros, diría magistrales, una cátedra teórica y una historia seductora que ayuda a comprender la totalidad de la producción del autor (en la línea del texto como propiedad privada); de la parodia, del pacto con el lector, de la noción de plagio, del peculiar destino de la cita en la literatura argentina y por extensión en la latinoamericana.

Este comienzo además es paradojal, ya que el relato que sigue destituye lo que está en juego: la propiedad de los textos, la idea del autor como dueño de su texto. Hay cuatro autores, Andreiev, Arlt, Kostia y Piglia; quienes son supuestos propietarios de un mismo relato: "Las tinieblas". El primero es el autor del cuento, el segundo lo plagia cambiando el título por el de "Luba"; Kostia lo publica bajo su nombre y Piglia lo vuelve a hacer en un libro de su autoría: Nombre falso, presentándolo como un inédito de Arlt. La historia secreta detrás de este juego nos dice que es Piglia el que plagia el cuento de Andreiev para atribuírselo a Arlt, siguiendo las recomendaciones de Macedonio Fernández que pensaba escribir un libro y publicarlo bajo el nombre de otro autor:

Una de las aspiraciones de Macedonio era convertirse en inédito. Borrar sus huellas, ser leído como se lee a un desconocido, sin previo aviso. Varias veces insinuó que estaba escribiendo un libro del que nadie nunca iba a conocer una página. En su testamento decidió que el libro se publicara en secreto, hacia 1980. Nadie debía saber que ese libro era suyo. En principio había pensado que se publicara como un libro anónimo. Después pensó que debía publicarse con el nombre de un escritor conocido. Atribuir su libro a otro: el plagio al revés (Piglia 1999: 31).

Siguiendo esta línea, Piglia plagia el cuento de Andreiev atribuyendo el plagio a Arlt, disimulando la operación bajo el supuesto descubrimiento de un inédito. Plagiar un libro y publicarlo con el nombre de un autor reconocido hace del plagio un doble atentado a la idea de original y al prestigio de la idea de autor, rebajándola a un dispositivo fraudulento, que, en los términos de Arlt, puede llamarse "escritor fracasado".

Piglia utiliza mecanismos de falsificación y de robo, la traducción como plagio, la combinación de registros, el entrevero de filiaciones para construir la parodia de un relato policial y la de un metatexto, con un apéndice que contiene el cuento "Luba", que también funciona como parodia de un plagio.

Inventar que existe un texto inédito de Arlt es una manera de borrar las huellas del plagio, crear una pista distractiva del robo, utilizando el léxico policial. Piglia plagia el 
cuento "Las tinieblas" y lo oculta, cambiándole el título por "Luba" y presentándolo como un original de Arlt. Transformar un plagio en un original es una operación clave del relato.

Hay aquí una representación casi paranoica del autor como sujeto que miente y falsifica. Esta representación está ya presente en otro texto que Piglia atribuye a Arlt (que en realidad es un mix de diversas "Aguafuertes" y reproduce en Nombre falso: "En nuestro tiempo el escritor se cree el centro del mundo" (Piglia 1994). Macanea a su gusto, engaña a la opinión pública. Todos nosotros los que escribimos y firmarnos, lo hacemos para ganarnos el puchero, nada más. Y para ganarnos el puchero no vacilamos en afirmar que lo blanco es negro y viceversa. La gente busca la verdad y nosotros le damos moneda falsa. Es el oficio, el metier, la gente cree que recibe la mercadería legítima y cree que es materia prima, cuando apenas se trata de una falsificación burda, de otras falsificaciones que también se inspiraron en falsificaciones (Piglia 1994: 91).

Desarrollando esta tesis, Piglia hace creer al lector que le entrega una mercancía legítima, un cuento inédito de Arlt cuando se trata de una falsificación de un cuento de Andreiev, una moneda falsa que pasa a ser propiedad final de Piglia al publicarlo en su libro. El fenómeno de la intertextualidad que aquí aparece, la relación con el texto de otro está cruzada por las relaciones de propiedad. Piglia (1994) decide robar un cuento de otro porque cree que los textos no tienen dueño y porque siguiendo -no sé si verazmente- a Melville, piensa que escribir es engañar, no poder decir nunca toda la verdad: "qué insensato, qué inconcebible que un autor -en ninguna circunstancia posible -pueda ser franco con sus lectores" (90). Además, la propiedad es un robo: "¿qué es robar un banco comparado con fundarlo?”. Esta última frase Piglia se la atribuye a un personaje llamado Rinaldi, pero pertenece a Brecht en La ópera de tres centavos donde el protagonista Machealt dice: "¿quién es un mayor criminal el que roba o funda un banco?" (Brecht 1957: 51).

La parodia del relato policial al proponer una búsqueda que no es tal, en cuanto al objeto buscado, es una invención del propio detective, tiene relación con la serie social de la época. Piglia escribe este relato en 1975 , a un año del golpe militar que se va a desarrollar como una gran farsa (la parodia) y un gran drama. La convulsión política del momento agudiza la concepción de la sociedad argentina que propone Piglia (2000): "la sociedad como una trama de relatos, un conjunto de historias y de ficciones que circulan entre la gente. Dentro de esta trama la política está basada en el complot, la conspiración. Ese es un relato bien argentino" (43).

La maquinación, el mecanismo oculto, 1a razón secreta construyen una visión conspirativa de la historia. En el marco del relato policial, Piglia representa esas fuerzas ficticias capaces de fundar el poder que se ejerce sobre la trama social. ¿Qué estructura tienen esas fuerzas ficticias? "Homenaje a Roberto Arlt" da una respuesta, la que corresponde a la esfera de la literatura, cuyo funcionamiento se puede homologar a las relaciones con que funciona la sociedad, que dicen que la estructura social es la propia de la falsificación y de la conspiración. Por tanto, el relato no solo habla de la serie literaria sino también de la social. "Homenaje" narra una historia ficticia que trabaja con los mismos elementos con que se organiza el poder en la sociedad argentina: una visión conspirativa de la historia 
que redunda en un relato falso. Tal como el relato de "sanación de la patria enferma" que inventan los militares para justificar el golpe de Estado de 1976 (Piglia 2000: 44). En este aspecto, como afirma con impresionante lucidez el mismo Piglia:

Por momentos la ficción del Estado aventaja a la novela argentina. Los servicios de información manejan técnicas narrativas más novelescas y eficaces que la mayoría de los novelistas argentinos. Y suelen ser más imaginativos. El único que los mantuvo a raya fue Roberto Arlt: les captó el núcleo paranoico, el complot, el crimen, la falsificación son la esencia del poder en la Argentina: eso narra Arlt. Escribió una obra que va a durar lo que dure el Estado argentino. Sus novelas son el doble microscópico y delirante del Estado nacional (Piglia 2000: 114-115).

Siguiendo esta propuesta, "Homenaje" narra una teoría literaria que es una visión miniaturizada de una teoría política paranoica sobre el Estado argentino.

A esta cuestión del poder hay que añadir dos elementos básicos. Uno, que lo reafirma y otro que lo resiste. El primero es el tema del dinero que considera a la literatura como una mercancía que circula entre lectores y críticos, idea tan afecta a Arlt y que se reproduce en el narrador de "Homenaje" que adquiere el supuesto inédito pagando cuarenta mil pesos. El dispositivo de resistencia al poder es el robo, el atentado contra la propiedad privada, que es el verdadero robo, resistencia que enlaza tres autores: Arlt, Borges y Piglia. En el caso de Borges basta pensar en "Pierre Menard autor del Quijote" y en su propuesta que existe un solo libro y autor, para confirmar el gran robo a la noción de autor como dueño de su texto. Hay aquí una doble proposición: la sociedad como una tierra de todos y de nadie y la literatura como un campo común al disolverse la idea de original y autor.

Pero este texto tiene una estructura doble: ensayo/cuento, relato de una investigación/relato de una persecución y utopía/ "macaneo". Esta última oposición enfrenta la utopía del fin de la noción de propiedad con la afirmación de Roberto Arlt, que el escritor macanea a gusto. El verbo macanear que proviene del lunfardo y significa mentir, falsear; es la réplica a nivel del lenguaje popular de la idea que plantea Borges en "El escritor argentino y la tradición": "La tesis central del ensayo de Borges es que las literaturas secundarias y marginales, desplazadas de las grandes corrientes europeas, tienen la posibilidad de un manejo propio e irreverente" (Piglia 1999), de las grandes tradiciones. Borges pone como ejemplo de esta colocación junto con la literatura argentina, a la cultura judía y a la literatura irlandesa:

Pueblos de frontera, que se manejan entre dos historias, en dos tiempos y a menudo en dos lenguas. Una cultura nacional dispersa y fracturada, en tensión con una tradición dominante de alta cultura extranjera. Para Borges (como para Gombrowicz) este lugar incierto permite un uso específico de la herencia cultural: los mecanismos de falsificación, la tentación del robo, la traducción como plagio, la mezcla, la combinación de registros (Piglia 2000: 36). 
En los términos de Arlt, un macaneo. El robo a la propiedad privada, repito, está basado en el campo de la literatura, en la idea que los textos son de nadie. Conforme a Nombre falso, para consumar el hurto se utiliza el plagio, la parodia, el pastiche y el apócrifo, que más allá de su función establecida, son en "Homenaje" dispositivos de rechazo de la privatización de la literatura.

Estos procedimientos desechan la concepción romántica, que es la que entroniza icónicamente la particularidad moderna de la apropiación de los textos: ellos tienen un dueño, el autor, de manera tal que otra respuesta posible, distinta a la de Foucault, a la pregunta ¿qué es un autor?, se puede responder: el dueño de un texto, tal como un individuo es dueño de su casa. La escritura pasa de la esfera pública y social a la privada. Así nace la idea del autor como propietario, los derechos de autor, la noción de originalidad y consecuentemente la del plagio.

Piglia en "Homenaje a Roberto Arlt" parodia estas nociones, tanto de la originalidad como del plagio y roba, como dije, el cuento de Andreiev para atribuírselo a Arlt y finalmente a sí mismo. Esta autoatribución preocupa a Piglia de modo tal que en la nota 16 del texto, que cumple, como las precedentes, de contribuir al carácter fidedigno de la investigación, se siente obligado a dar una explicación:

Se dirá que me aparto del objetivo de este informe: no es del todo así. El hecho de que al presentar un texto inédito de Roberto Arlt me haya visto forzado a usar la forma del relato, el hecho que el cuento de Arlt se lea en el interior de un libro de relatos que aparece con mi nombre, es decir el hecho que no me haya sido posible publicar este texto -como había sido mi intención- independientemente, precedido por un simple ensayo introductorio, demuestra ya se verá que de algún modo he sido sometido a la misma prueba que Max Brod (Piglia 1994: 121).

La alusión a Max Brod se ha desarrollado al principio de la nota 16, de la que transcribí la última parte, y hace mención a la historia de las relaciones entre Kafka y Brod, cuando el primero antes de morir le ordena a su amigo que queme todos sus manuscritos, entre ellos El castillo y El proceso, como si nunca hubieran sido escritos. Max Brod se ve envuelto en una clásica situación kafkiana: está obligado a traicionar a su amigo no cumpliendo su orden o traicionar a la literatura quemando los manuscritos. Pero existe otra posibilidad, si nadie conocía estos manuscritos ipor qué Brod no podría haberlos publicado bajo su propio nombre? Así habría conseguido fama universal. Brod no lo hace actuando como un Eróstrato (figura que fascinaba a Kafka) al revés.

Brod no está dispuesto a cometer un delito para conseguir la fama. Piglia si lo está, si consideramos el plagio como un acto delictivo. Pero como el acto se lo atribuye a Arlt no hay delito, sino traición. Y aquí nos hallamos frente a un punto neurálgico del relato: Piglia para rendirle un homenaje a Arlt utiliza la traición. Si la palabra homenaje significa acto de celebración en honor a alguien, ¿̇dónde está la celebración? Creo que "Homenaje" hay que entenderlo en forma peculiar como rescate. Piglia rescata a Arlt del olvido, o en el mejor de 
los casos, de la subalternidad que ha ocupado en la historia literaria argentina. ¿Qué consigue con el fraude? Revivir la figura de Arlt, ponerlo en primera plana ante críticos y lectores al anunciar y publicar un inédito, de forma tan convincente que algunos especialistas arltianos celebran la aparición de "Luba" como rescate de un texto perdido del autor (Hayes 1987). En cuanto a la traición, Piglia no sigue el modelo de Brod, sino el del Judas borgeano en "Tres versiones de Judas", en el que la traición es un homenaje desgarrador a Cristo ( $\mathrm{Si}$ Cristo se rebajó a ser hombre, lo único condigno de tamaño sacrificio era asumir el peor de los delitos: la traición). Piglia traiciona a la literatura y traiciona a Arlt, pero la doble traición se vuelve homenaje, si pensamos en Judas.

En todo este proceso el escritor actúa como un falsario que borra sus huellas para poder traicionar. Naturalmente, hay aquí una traición al lector. También doble porque además nunca se dice lo más importante: que el plagio es una invención de Piglia. Es claro que si lo dijera no habría cuento. Similar es el caso de un relato de Borges, "Hombre de la esquina rosada", donde el discurso narrativo e historia están marcados por la traición (el crimen es un acto traicionero y nunca se dice lo más importante, quien mató al corralero). "Un hombre muerto a puntapiés" de Palacio también trabaja con la traición. El dato fundamental que el narrador es el criminal se escamotea constantemente; nunca se le dice al lector tal cosa. Estos relatos de vanguardia rompen el pacto canónico con el lector, fundado en que el narrador siempre va a decir la verdad.

Como consecuencia de la traición, del crimen y el ocultamiento, el papel del crítico asume el rol del detective, alguien que rastrea en la trama narrativa pistas de la traición del autor criminal. Escribir es traicionar según estos relatos. Pero el vocablo traición no debe entenderse en el nivel moral. Por el contrario, en los textos vanguardistas citados significa que se traiciona al canon, al idealismo romántico y al pragmatismo realista, incluso la moral de la clase a la que pertenece el autor. Desde esta última perspectiva la traición es un acto de subversión.

Es clave leer bien las pistas y recobrar las huellas que el autor va borrando. Leer mal es fatal porque muchas veces el relato es una telaraña destinada a atrapar al lector; como ocurre en la "La muerte y la brújula" de Borges; donde Lonnrot, el detective, es capturado y eliminado por el criminal Scharlach. Para Piglia la relación entre el detective y el criminal equivale a la del lector y el autor, equivalencia ya propuesta por Chesterton. Se escribe para un lector previsto al que se quiere engańar y atrapar, pero el crítico, como lector superior denuncia la trampa.

El crítico detective que funciona en "Homenaje" tendría que demostrar que el autor es un falsario que pasa mercadería falsa por legítima y que su figura implica la noción de propiedad, que es el mayor robo. Sin embargo, no lo hace, y no trepida en traicionar al homenajeado y a la figura del investigador. Traición que se basa en que nunca se narra lo más importante, aunque se prometa una y otra vez hacerlo.

Piglia manipula al lector sin decirle nunca la verdad: no hay tal inédito de Arlt. Toda la narración está construida sobre una falsedad que nunca se declara, aunque el autor deja huellas de ese proceder: 
Era una caja de metal, una de esas cajas que se usan para guardar dinero. Adentro encontré la explicación del motivo que había decidido a Kostia a publicar el relato de Arlt con su nombre. En medio del polvo y pegoteados con una sustancia gomosa que parecía caucho líquido había tres billetes de un peso, varias muestras del tejido de las medias engomadas, un ejemplar de Las tinieblas de Andreiev (Piglia 1994: 129).

La mención al texto del autor ruso nos entrega la pista clave para acceder a lo que no se cuenta en el relato y explica por qué Kostia publicó "Luba" bajo su nombre: proteger a Arlt de la acusación de plagio.

En síntesis, en "Homenaje" nunca se narra lo más importante, ya que decirlo significa, precisamente, no poder narrar. En esta línea puedo decir que en 1998 Piglia me entregó en la librería Orfeo de Buenos Aires, un cuento para ser publicado en la Revista Atenea que en esa época yo dirigía. Al relato le faltaba el título y un cambio en la parte final que quedó de enviarme, pero como nunca lo hizo el texto permanece inédito. Lo que sí publiqué fue una excelente entrevista que le hizo el recordado poeta argentino Jorge Ariel Madrazo.

Es evidente que no solo existe un "macaneo" con la idea de autor, con la forma canónica del relato policial y el modelo de la investigación filológica, sino también con la noción de metatexto. La conclusión dominante que nos entrega la exposición sobre los modos de producción del texto, la función del autor y del lector es que la literatura es una mercancía que circula entre autores y lectores de un modo semejante al que circula entre los clientes el cuerpo de la prostituta Luba. Ella actúa como si fuera una señorita de familia burguesa y no una mujer que vende su cuerpo. La literatura representa la misma farsa, según Arlt: puede ofrecerse como utopía, como subversión permanente, pero lo que la mueve al final es el dinero, ella es una prostituta disfrazada de señorita.

¿Podemos atribuirle al autor Piglia, que es el nombre del narrador del relato, esta concepción cínica, descreída y amarga de la creación literaria? A juzgar por lo expuesto visiblemente en la narración, sí es posible. Pero en este punto se abre el nuevo enfoque que propongo sobre el relato. El mismo Piglia (1999) ha señalado en Formas Breves que un cuento siempre narra dos historias: la historia visible y otra secreta (92). Hasta ahora me he movido en el plano de la historia visible, como lo ha hecho toda la crítica precedente (con la gran excepción de Fornet, y los buenos aportes de Rovira) porque pareciera que no se cumple la premisa pigliana que afirma la presencia siempre recurrente de la historia secreta. Pero ella existe, aunque muy disimulada, en lo que se ha considerado la segunda parte del relato: el apéndice que contiene el supuesto inédito de Arlt, "Luba". Fornet (1994), en uno de los mejores análisis de "Homenaje a Roberto Arlt", plantea que el relato se divide en dos partes: "la primera bajo la forma de una pesquisa bibliográfica y la segunda de una historia de persecución en el apéndice Luba" (113). Mi proposición considera la íntima unidad de ambas partes, de modo tal que se debe hablar de una sola, bajo la tesis de Piglia de las dos historias. Primeramente, se narra una historia de codicia bajo la forma de la pesquisa bibliográfica, donde participan Arlt, Piglia y Kostia. EI primero cobrando 
por página escrita y plagiando porque no tiene tiempo para escribir por su codicioso y absorbente experimento con las medias engomadas con el cual pensaba hacerse rico. Piglia (1994), ávido del supuesto inédito, actúa como un negociante: "Fíjese -le dije yo-, ansioso por revisar el manuscrito, si encuentra algo tráigalo a mí, no hable con nadie” (93), y Kostia que cobra cuarenta mil pesos por entregar el manuscrito. Ellos son los actores que pagan y cobran y ven en la literatura un negocio. Se conforma, así, una historia antiutópica que incluye a la literatura en las relaciones capitalistas. Pero hay otra que se desarrolla en los intersticios de la persecución que se narra en "Luba” y que cuenta una historia de redención, una utopía que tiene como protagonistas al anarquista y a la mujer. Aquí no hay codicia, no es el dinero el que mueve las conductas, sino la amistad, la lealtad, los ideales:

Él empieza a hablarle, sosegado, en voz baja, como un viejo que le contara a los niños un cuento heroico de los tiempos antiguos. Y en la penumbra rojiza de la pequeña habitación, que parece agrandarse ante los ojos mansos de Luba, pasan un puñado de hombres jóvenes, soñando un porvenir lejano, soñando a los hombres hermanos que no han nacido aún pero ya están en la vida como fantasmas pálidos (Piglia 1994: 151).

Los personajes de la historia secreta sueñan con un porvenir despojados de la codicia y las máscaras que ella engendra. En este sentido, es fundamental que Luba se despoje de este nombre falso y asuma el verdadero: "No me llamo Luba -dice ella, apretando la valija contra su cuerpo-. Mi verdadero nombre es Beatriz Sánchez” (Piglia 1994: 1953).

Desde esta perspectiva, se explica uno de los motivos de elección del cuento de Andreiev como supuesto texto de Arlt. El relato del autor ruso y las variaciones que introduce Piglia, especialmente la modificación del final del cuento, permiten contar una contra historia utópica frente a la narración antiutópica del plagio. Una historia de redención, la de Beatriz Sánchez y el anarquista, en oposición a la de codicia de Arlt y Piglia. Pero existe otra explicación mucha más ambigua. La escritura propia del realismo decimonónico que utiliza Andreiev se empareja con la de Arlt, que, según una visión preponderante de la crítica al uso, como la de Mirta Arlt que escribe: "Pero en cuanto a la técnica literaria y, cuestiones de carácter lingüístico no veo nada innovador, sino solo defectos que resaltarían de la difícil situación social y familiar del autor" (Jordan 2007: 25).

A la ambigüedad de esta tesis es preferible oponer la opinión de Fornet muy clarificadora:

En cualquier caso, queda claro que la elección de Andreiew como objeto de plagio está lejos de ser gratuita. Lo importante es que Piglia una todo este juego porque ve relaciones profundas entre uno y otro autor, porque nota que de la conjunción de ellos puede salir algo nuevo. De hecho (lo ha subrayado) un escritor es alguien que traiciona lo que lee, que desvía y ficcionaliza: hay como un exceso en la lectura que hace Borges de Hernández, o en la lectura que hace Olson de Melville, o 
Gombrowigz de Dante, hay cierta desviación de esas lecturas, un uso inesperado de otro texto (Fornet 1994: 110).

En todo caso, la tesis de la unidad del relato que propongo se fundamenta en el hecho que "Luba" revela su sentido secreto solo si lo oponemos al de la pesquisa bibliográfica inicial. A propósito del motivo de la pesquisa, me permito argüir que este es otro elemento de unidad de las dos supuestas partes, ambas narran lo mismo: una persecución. En una se persigue un texto, en otra a un hombre.

Si funciona lo que he propuesto, Piglia no solo trabaja con la categoría arltliana del macaneo, sino en contraposición, con la utopía, que siguiendo su propia dirección señala que: "Hay siempre un fundamento utópico en la literatura. En última instancia la literatura es una forma privada de la utopía" (Piglia 2000: 102). De aquí proviene la peculiar estructura de "Homenaje a Roberto Arlt", contar una historia de codicia y su contraposición, otra de generosidad redentora bajo la forma engañosa de un falso inédito de Arlt. La redención se vislumbra bellamente en el final modificado por Piglia del cuento de Andreiev:

En el espejo de marco dorado Luba y el hombre son dos figuras oscuras y frágiles.

Cuando abren la puerta, el aire dulce de la noche lluviosa les moja la cara. La ciudad brilla, quieta en la oscuridad. Al fondo las luces de Retiro arden como un fuego pálido.

\section{-Vamos Luba -dice él.}

No me llamo Luba -dice ella, apretando la valija contra su cuerpo. Mi verdadero nombre es Beatriz Sánchez (Piglia 1994: 153).

El espejo de marco dorado que anuncia el espejeo de la noche, la lluvia bautismal que lava los rostros de la pareja, las luces que brillan indican que el camino ha terminado y comenzado el viaje hacia el futuro. Sin embargo, la historia secreta es más compleja y para entenderla por completo, si ello es posible, es preciso perseguir otras pistas. Puedo comenzar por el epígrafe que encabeza Nombre falso "Solo se pierde lo que realmente no se ha tenido"; Piglia atribuye la frase a Roberto Arlt, pero esta es de Borges (1996): "Nadie pierde (repites vanamente) sino lo que no tiene y no ha tenido nunca", verso que pertenece al poema "1964" de El otro, el mismo (128).

El procedimiento de la cita errónea es cultivado casi hasta la exasperación por Borges, como lo señala el propio Piglia (2008) en Crítica y ficción (87). También es de Borges la idea que el autor es una figura intercambiable, específicamente por la figura del lector, como sucede en "Pierre Menard autor del Quijote". La parodia del policial fue cultivada reiteradamente por el mismo autor. Está demás decir que ninguno de estos procedimientos atrajo a Roberto Arlt, por lo que "El Homenaje", en cuanto a sus dispositivos de construcción 
sigue a Borges y no a Arlt, de tal modo que podría concluir que el homenajeado es el primer autor y no el segundo.

Pienso al respecto, recurriendo al mecanismo de las dos historias, que la visible es un homenaje a Arlt, que contiene en sus intersticios la historia secreta que homenajea a Borges, cuestión que ya había advertido Jitrik (1976), aunque de un modo distinto al que hago aquí.

Doble homenaje que reúne a dos autores y que la crítica ha separado siempre por disímiles, por constituir los polos opuestos de la tradición narrativa argentina: Borges el que escribe bien y Arlt el que escribe mal, frase que repito por comodidad, pero que de ningún modo comparto, ¿qué es escribir bien o mal?

Homenajear a Arlt con procedimientos propios de Borges y hacerlo con éste desarrollando la idea de la literatura como mercancía, que propone Arlt, según Piglia, es un tour de force admirable que sitúa "Homenaje a Roberto Arlt" como un texto clave de la literatura hispanoamericana. Clave, entre otras razones, porque demuestra que se puede narrar una idea, una teoría, la del plagio en este caso, ficcionalizándola como si se tratara de un viaje o una historia policial. Es decir, presenta un tema que proviene desde los textos fundacionales de la literatura hispanoamericana moderna: las relaciones del pensamiento con la literatura. Podría decir que el pensamiento filosófico hispanoamericano más consistente está contenido en obras literarias fundadoras como El Facundo de Sarmiento o Ficciones de Borges, restringiéndome a la literatura argentina; o en las artes poéticas de Vallejo, Huidobro, Neruda, José Emilio Pacheco. Es allí donde debe buscarse, en buena medida, la originalidad y el aporte a la filosofía de este pensamiento creador.

Piglia complica este tema, de por sí complejo y polémico, cuando introduce la figura de Macedonio Fernández, atribuyéndole una opinión al respecto: "Le parece posible que en una novela puedan expresarse pensamientos tan difíciles y de forma tan abstracta como en una obra filosófica, pero a condición de que parezcan falsos. 'Esa ilusión de falsedad, dijo Renzi', es la literatura misma" (Piglia 2000: 28).

La literatura como ilusión de falsedad se opone radicalmente a la idea canónica de la literatura como ilusión de realidad y obliga a repensar el tema. Primeramente, se trata de aquellas novelas que expresan narrativamente pensamientos abstractos propios del discurso filosófico. En segundo lugar, su transformación en el motivo narrativo solo se produce si se le presenta como falsedad. ¿Cómo entenderlo? Nombre falso indica una pista: se trata de un homenaje doble, como dije. El primer homenajeado, Arlt, escribe pensando que la literatura entrega una ilusión de realidad; Borges, el segundo, por el contrario, que es la ilusión de falsedad la que determina la creación literaria. Piglia el autor que convoca a Arlt y Borges trabaja literariamente con las dos opciones, más estrictamente, trabaja "entre" las dos siguiendo las proposiciones de Deleuze sobre el concepto de "entre" (Deleuze 2004: 41) y oscilando constantemente. Hay en Piglia una representación simultánea de la realidad como drama y como farsa, que vuelve muy atractiva sus novelas, como es el caso de Plata quemada inspirada en un hecho real dramático propio de la crónica roja (ilusión de realidad) pero narrado como un incidente farsesco, como un malentendido colosal sobre qué significa 
quemar el dinero obtenido en el atraco tanto por parte de los ladrones como de la policía y los espectadores, lo que contribuye a la ilusión de falsedad.

Hermoso y seductor relato el de "Homenaje" que narra dos historias contrapuestas, una de codicia y otra de generosidad solidaria, que rinde un doble homenaje: a Borges y Arlt, que cumple el sueño de Macedonio Fernández: plagiar un cuento y atribuírselo a otro, que narra una teoría sobre el plagio siguiendo al mismo Macedonio y que contiene una pequeña utopía privada: la irrenunciable necesidad de renunciar al nombre falso.

Por último, escribir en "Homenaje" equivale a robar, todo lo contrario de plagiar (Deleuze 1980: 11) y significa también traicionar, como dije no en el sentido moral corriente, sino en el ético y político: traicionar significa subvertir el canon del relato policial, la moral de una clase y rechazar el mecanismo del nombre falso que trabaja con el disfraz, con la alusión a lo extraño que linda con lo exótico: "No me llamo Luba dijo ella mi nombre es Beatriz Sánchez". La máscara del nombre extraño desplazada por la realidad de un nombre propio corriente y habitual. Aquí encontramos conviviendo la ilusión de falsedad, Luba, con la de realidad, Beatriz Sánchez. Puedo decir como corolario, que "Homenaje" se desliza entre ambas ilusiones, y que en el mostrar esa seductora forma del deslizamiento, su maestría, reside mi homenaje a Ricardo Piglia.

\section{OBRAS CITADAS}

Berg, Edgardo. 1998. "Ricardo Piglia lector de Borges”. Revista Iberoamericana 69: 49. Borges, Jorge Luis. 1996. Obras completas. Barcelona: Emecé Editores.

Bretch, Bertold. 1957. La ópera de tres centavos. Buenos Aires: Ediciones Losange.

Casarín, Marcelo. 2007. "La escritura de Ricardo Piglia: los rastros de una pesquisa". Anales de Literatura Hispanoamericana: 103-109.

Deleuze, Gilles. 2004. Diálogos. Valencia: Pre-textos.

Deredita, John F. 1980. “¿Es propiedad? Indeterminación genérica, intertextualidad, diseminación en un texto de Ricardo Piglia”. En Texto/contexto en la literatura iberoamericana. Instituto Internacional de Literatura Iberoamericana. Madrid: 61-69.

Di Maglio, Mariangel. 2003. "El valor de la letra: las versiones especulares" en Nombre Falso en https://webs.ucm-es/info/especulo/numero31/nombrefa.html.

Fornet, Jorge. 1994. "Homenaje a Roberto Arlt o la literatura como plagio". Nueva Revista de Filología Hispánica 1.XLII: 135.

Gnutzmann, Rita. 1992. "Homenaje a Arlt Borges y Onetti de Ricardo Piglia”. https:/ Revista iberoamericana.pitt edu/ojs /index php/iberoamericana/article/.../5201.

Goloboff, Gerardo Mario. 1975. "La primera novela de Roberto Arlt: el asalto a la literatura". Revista Literaria Latinoamericana 2: 35.

Gonzalez Álvarez, José M. 2009. En los “bordes fluidos”. Formas hibridas y autoficción en la escritura de Ricardo Piglia. Berm: Peter Lang.

Hayes, Aden. 1987. "La revolución y el prostíbulo. Luba de Roberto Arlt". Ideologies and 
Literature 2.1: 141-147.

Jitrik, Noé. 1976. "En las manos de Borges el corazón de Arlt. A propósito de Nombre falso de Ricardo Piglia”. Cambio 3: 89.

Jordan, Paul. 2007. "Roberto Arl y los años sesenta: crítica y recepción”. Fragmentos.

Revista de lingua e literatura estrangeiras 32: 23-32.

McCracken, Ellen. 1991. "Metaplagiarism and the critic's role as detective: Ricardo Piglia's reinvention of Roberto Arlt". PMLA 106: 1073.

Pereira, María Antonieta. 1999. "Ricardo Piglia y la máquina de ficción”. Estudios Filológicos 34: 27-34.

Piglia, Ricardo. 1973. "Roberto Arlt: una crítica de la economía literaria”. Los libros 29. . 1974. "Roberto Arlt: la ficción del dinero". Hispamérica 7: 25-28. . 1994. Nombre falso. Barcelona: Seix Barral. . 1999. Formas breves. Buenos Aires: Temas Grupo Editorial. . 2000. Critica y ficción. Barcelona: Anagrama.

Rovira Vásquez, Gabriel. 2015. Lo que Ricardo Piglia oculta: una poética de la ficción. México: Universidad Autónoma de Baja California Sur. 